BMJ Open

Diabetes

Research

\& Care

\section{Therapy adjustments in people with type 1 diabetes with impaired hypoglycemia awareness on multiple daily injections using real-time continuous glucose monitoring: a mechanistic analysis of the HypoDE study}

To cite: Waldenmaier $D$ Freckmann G, Pleus S, et al. Therapy adjustments in people with type 1 diabetes with impaired hypoglycemia awareness on multiple daily injections using realtime continuous glucose monitoring: a mechanistic analysis of the HypoDE study. BMJ Open Diab Res Care 2021;9:e001848. doi:10.1136/ bmjdrc-2020-001848

Parts of the data were already presented at the 54th Annual Meeting of the European Association for the Study of Diabetes (EASD), 1-5 0ctober 2018 in Berlin, and at the 54th Diabetes Congress of the German Diabetes Association (DDG), 29 May to 1 June 2019 in Berlin.

Received 25 August 2020 Revised 26 February 2021 Accepted 28 March 2021

Check for updates

C Author(s) (or their employer(s)) 2021. Re-use permitted under CC BY-NC. No commercial re-use. See rights and permissions. Published by BMJ.

For numbered affiliations see end of article.

Correspondence to Delia Waldenmaier; delia.waldenmaier@idt-ulm.de

\section{ABSTRACT}

Introduction Studies have shown beneficial effects of real-time continuous glucose monitoring (rtCGM) usage on clinical outcomes. The objective of this analysis was to identify which therapy adjustments were made by people with type 1 diabetes with impaired hypoglycemia awareness during rtCGM usage enabling reductions in the number of low glucose events observed in the HypoDE (Hypoglycemia in Deutschland) study.

Research design and methods In the multicenter randomized controlled trial in people with type 1 diabetes on multiple daily injections with impaired hypoglycemia awareness, participants recorded their diabetes therapy in 7-day logbooks at baseline and at 6-month follow-up. They used rtCGM or selfmonitoring of blood glucose for therapy adjustments This mechanistic analysis looked at changes in various aspects of therapy.

Results Logbooks were completed by 70 participants in the rtCGM group and 65 participants in the control group. Participants in the rtCGM group kept their total carbohydrate consumption, daily insulin doses and distribution constant during the study. However, they reported an increased intake of rescue carbohydrates $(0.8 \pm 0.6($ mean $\pm S D)$ vs $1.0 \pm 0.8$ intake/day; baselineadjusted between-group difference 0.3 intake $(0.1-0.5)$, $\mathrm{p}=0.031$ ). The glucose threshold at which rescue carbohydrate intake was initiated was elevated from $71 \pm 13 \mathrm{mg} / \mathrm{dL}(3.9 \pm 0.7 \mathrm{mmol} / \mathrm{L})$ to $79 \pm 14 \mathrm{mg} / \mathrm{dL}$ $(4.4 \pm 0.8 \mathrm{mmol} / \mathrm{L})$ (adjusted between-group difference $+7.6 \mathrm{mg} / \mathrm{dL}(2.4-12.8)(+0.4 \mathrm{mmol} / \mathrm{L}(0.1-0.7))$; $\mathrm{p}=0.005$ ) in the rtCGM group. Regression analysis showed that follow-up low glucose events were associated with group allocation $(p<0.001)$, low glucose events at baseline $(p=0.016)$ and rescue threshold $(p=0.001)$.

Conclusions No major adjustments in insulin therapy were made by study participants with impaired hypoglycemia awareness; however, they were more active in preventing hypoglycemia by taking rescue carbohydrates earlier and more often.

Trial registration number NCT02671968.

\section{Significance of this study}

What is already known about this subject?

- Real-time continuous glucose monitoring (rtCGM) has been shown to improve $\mathrm{HbA} 1 \mathrm{c}$ and to reduce hypoglycemia in people with type 1 diabetes; however, the mechanisms behind these beneficial effects have not been systematically investigated.

What are the new findings?

- This study showed that participants with impaired hypoglycemia awareness using rtCGM did not systematically change their therapy regarding insulin therapy and nutrition.

- Participants were more active in preventing hypoglycemia by taking rescue carbohydrates earlier and more often.

How might these results change the focus of research or clinical practice?

- The full potential of rtCGM might still not be exhaustively used.

\section{INTRODUCTION}

Real-time continuous glucose monitoring (rtCGM) systems continuously provide current glucose levels and further information to support the user in making adequate therapeutic decisions. In addition, rtCGM systems provide alarms for low and high glucose levels that allow intervention (eg, rescue carbohydrates in case of low glucose values or additional insulin in case of high glucose values).

Randomized controlled trials have shown that rtCGM is helpful to improve HbAlc levels ${ }^{2}$ and has beneficial effects in people with type 1 diabetes and hypoglycemia problems. A first study in 2013 showed a 
significant reduction in the incidence of clinical hypoglycemia, defined as moderate and severe hypoglycemic events, as well as biochemical hypoglycemia, in children and adults with type 1 diabetes using a glucose sensor-augmented pump therapy compared with pump therapy with self-monitoring of blood glucose (SMBG). ${ }^{3}$ The IN CONTROL study reported less biochemical hypoglycemia and fewer severe hypoglycemic events in participants using rtCGM compared with SMBG users in a risk group of people with type 1 diabetes and an impaired awareness of hypoglycemia. ${ }^{4}$ The HypoCOMPaSS (Comparison of Optimised MDI versus Pumps with or without Sensors in Severe Hypoglycemia) study even showed a sustainable improvement of hypoglycemia awareness. ${ }^{5}$ Additionally, the HypoDE (Hypoglycemia in Deutschland) study provided evidence that rtCGM usage significantly reduces occurrence of low glycemic events and severe hypoglycemia in people with type 1 diabetes on multiple daily injections (MDI) that have an increased risk for hypoglycemia. ${ }^{6}$

In general, the benefits of rtCGM were demonstrated in people with type 1 diabetes using insulin pump therapy, ${ }^{37}$ as well as MDI, ${ }^{8}$ or both insulin application forms. ${ }^{4}$ This might indicate that for hypoglycemia avoidance diabetes self-management of the rtCGM users is more important than the insulin application by insulin pump or MDI.

However, little is known about how users of rtCGM actually use the advantages that rtCGM has to offer in their daily life for the avoidance of hypoglycemia. In principle, there are two possibilities how rtCGM can help to avoid hypoglycemia. First, glucose courses can be retrospectively analyzed to detect problematic glucose patterns. Based on such analyses, adjustments of basal or prandial insulin doses or modifications to insulin-to-carbohydrate factors can be made. Second, alarms and real-time data can merely be used for corrective actions, that is, intake of carbohydrates when glucose levels are low.

In most studies on rtCGM, participants' reactions towards low glucose values were not systematically assessed or no systematic adjustments to rtCGM data were reported. ${ }^{4-10}$ Therefore, it is not obvious whether systematic changes in insulin therapy or behavioral changes contributed more to improvements of hypoglycemia problems. Thus, mechanisms linking rtCGM and beneficial effects on glycemic outcomes remain unclear, in spite of a long-standing knowledge about the efficacy of rtCGM concerning hypoglycemia problems. In addition, it is important to assess the relative importance of different mediating factors among other potential treatment factors (eg, insulin dose, distribution of basal/bolus insulin dose, number of injections). Knowledge about these potential effects could, however, help increase our understanding of the potential of rtCGM.

In the HypoDE study, changes in diabetes therapy were recorded by means of baseline and follow-up logbooks. The aim of this secondary analysis of the HypoDE study was to identify possible associations between rtCGM use and improvements in clinical outcomes.

\section{RESEARCH DESIGN AND METHODS}

The HypoDE study was a multicenter randomized controlled trial in people with type 1 diabetes on MDI and an increased risk for hypoglycemia. The study is registered with ClinicalTrials.gov. From 12 specialized practices in Germany, 170 possible participants were recruited. Participants were eligible for the study if they were $\geq 18$ years old, had type 1 diabetes treated with MDI, an $\mathrm{HbAlc} \leq 9.0 \%(\leq 75 \mathrm{mmol} / \mathrm{mol})$ and a higher probability for hypoglycemic events, defined as having had at least one severe hypoglycemia in the previous year or hypoglycemia unawareness (defined by a score $\geq 4$ in the hypoglycemia unawareness questionnaire by Clarke et $\left.a l^{11}\right)$. Participants were not eligible if they used an insulin pump, had used a CGM system in the previous 3 months or were pregnant. Further details of the HypoDE study design were published previously. ${ }^{12}$

The primary outcome was a reduction in the occurrence of low glucose events $(\leq 54 \mathrm{mg} / \mathrm{dL}, \leq 3.0 \mathrm{mmol} / \mathrm{L})$ in participants using an rtCGM system compared with participants using SMBG. The study included a 4-week baseline phase during which all participants followed their routine SMBG-based therapy and additionally had a blinded CGM system (Dexcom G4 with 505 software, Dexcom, San Diego, California, USA) for data collection. All participants received a basic CGM training in order to be able to apply and calibrate the CGM system. After completion of the baseline phase, participants were randomized to either the rtCGM group that used a nonblinded rtCGM system (Dexcom G5 Mobile, Dexcom) or the control group that continued SMBG for the following 22 weeks. Central randomization was done with a 1:1 allocation using the study center as stratifying variable. Participants in the rtCGM group received a detailed CGM training including interpretation of data and making appropriate therapeutic decisions. The urgent low glucose alarm at $55 \mathrm{mg} / \mathrm{dL}(3.1 \mathrm{mmol} / \mathrm{L})$ could not be turned off and was therefore used by all participants; other alarm thresholds were set on an individual basis. Participants in the SMBG group performed at least four SMBG measurements per day and continued their therapy as usual. Study physicians were asked to review the available SMBG or rtCGM data during study visits or phone calls (three visits and three phone calls between randomization and follow-up) and discuss therapy modifications as appropriate with the participants. A resource kit including recommendations for therapy adjustments was available for both study groups. After 22 weeks, participants of the control group received a blinded CGM system for the 4-week follow-up phase, while participants in the rtCGM group continued regular rtCGM use. After 26 weeks, the study was completed. Device data were downloaded after the baseline and the follow-up phase.

The presented explorative analysis is based on an additional collection of therapy data by means of participant logbooks. Each participant was asked to keep a logbook for 7 consecutive days during the baseline phase and 
Table 1 Baseline characteristics of participants included in this evaluation

\begin{tabular}{|c|c|c|}
\hline & $\begin{array}{l}\text { Control group } \\
n=65\end{array}$ & $\begin{array}{l}\text { rtCGM group } \\
\mathrm{n}=70\end{array}$ \\
\hline Age (years) & $47.1 \pm 10.1$ & $45.7 \pm 11.7$ \\
\hline Women & $20(31 \%)$ & $31(44 \%)$ \\
\hline Men & $45(69 \%)$ & $39(56 \%)$ \\
\hline $\begin{array}{l}\text { Diabetes duration } \\
\text { (years) }\end{array}$ & $21.0 \pm 13.1$ & $20.9 \pm 14.1$ \\
\hline BMI $\left(\mathrm{kg} / \mathrm{m}^{2}\right)$ & $26.1 \pm 4.7$ & $26.2 \pm 6.7$ \\
\hline $\mathrm{HbA} 1 \mathrm{c}(\%(\mathrm{mmol} / \mathrm{mol}))$ & $7.4 \pm 1.0(57 \pm 10)$ & $7.5 \pm 1.0(58 \pm 10)$ \\
\hline $\begin{array}{l}\text { Severe hypoglycemia } \\
\text { in the last } 12 \text { months }\end{array}$ & $41(63 \%)$ & $45(64 \%)$ \\
\hline $\begin{array}{l}\text { Hypoglycemia } \\
\text { unawareness }\end{array}$ & $59(91 \%)$ & $66(94 \%)$ \\
\hline \multicolumn{3}{|l|}{ Basal insulin } \\
\hline Insulin degludec & $8(12 \%)$ & $5(7 \%)$ \\
\hline Insulin detemir & $22(34 \%)$ & $24(34 \%)$ \\
\hline Insulin glargine & $30(46 \%)$ & $35(50 \%)$ \\
\hline NPH insulin & $2(3 \%)$ & $4(6 \%)$ \\
\hline More than one & $1(2 \%)$ & $1(1 \%)$ \\
\hline Not known & $2(3 \%)$ & $1(1 \%)$ \\
\hline \multicolumn{3}{|l|}{ Bolus insulin } \\
\hline Insulin aspart & $24(37 \%)$ & $31(44 \%)$ \\
\hline Insulin glulisine & $8(12 \%)$ & $6(9 \%)$ \\
\hline Insulin lispro & $26(40 \%)$ & $23(33 \%)$ \\
\hline Regular insulin & $5(8 \%)$ & $7(10 \%)$ \\
\hline More than one & $1(2 \%)$ & $2(3 \%)$ \\
\hline Not known & $1(2 \%)$ & $1(1 \%)$ \\
\hline
\end{tabular}

Data are mean $\pm S D$ or total number and percentages.

BMI, body mass index; NPH, neutral protamine Hagedorn; rtCGM, real-time continuous glucose monitoring.

again for 7 consecutive days during the follow-up phase. In this logbook, all blood glucose measurements, basal and bolus insulin doses for meals or correction, any carbohydrate intake and estimated carbohydrate content should be documented by the participants themselves. Basic information like glucose target ranges or type of insulin was documented by means of a questionnaire. Respective rtCGM and SMBG data were added to the records afterwards.

Participants were included in the analysis if at least notes from 5 valid days were available in the logbooks for both study phases. All logbooks were checked for plausibility regarding availability of meal and insulin entries for all days and no obviously implausible entries in consideration of the CGM curves. If specific information, for example, carbohydrate estimations, was not available or not valid for the individual participants, this particular variable was not included in the analysis. Missing values were not replaced.
The following variables were calculated from logbooks: total daily basal and bolus insulin doses and insulin correction factors (ie, expected decrease of blood glucose $(\mathrm{mg} / \mathrm{dL}$ or $\mathrm{mmol} / \mathrm{L})$ after delivery of $1 \mathrm{U}$ of insulin), daily carbohydrate consumption and insulin to carbohydrate ratios. Considering the specific population group, fast-acting carbohydrates consumed for prevention or treatment of hypoglycemia (rescue carbohydrates) were regarded as meals of special interest. Rescue carbs were identified from logbooks as carbohydrate intake without insulin delivery and a glucose value below the individual target range. For each rescue carbohydrate intake, the corresponding glucose value was identified for calculating the patient-specific rescue threshold.

To analyze the change of these variables in participants using rtCGM, analysis of covariance of follow-up results using the randomization group as independent variable and the baseline values as well as intraindividual dispersion (number of contribution events per day and coefficient of variation between analyzed days) as covariates was performed. Results are presented as mean baselineadjusted between-group differences including 95\% CIs. No post hoc correction was performed due to the exploratory nature of the analysis.

To determine the effects of the different variables on the frequency of low glucose events, negative binomial regression analysis was performed using the follow-up low glucose events as dependent variable and randomization group, low glucose events at baseline and all variables that showed significant differences between groups in the analysis of covariance as predictors. Additionally, number of contributing events and variation within each participant over the 7 days were included to adjust for these repeated measures. For the regression analysis, missing values were replaced by means.

All statistical analyses were performed using SPSS V.26.0 for Windows (IBM).

\section{RESULTS}

The HypoDE study was completed by 141 participants (66 control group and 75 rtCGM group), of whom 135 completed the logbook and were thus included in the analysis. Of those, 65 were in the control group and 70 in the rtCGM group. Baseline participant characteristics are shown in table 1 .

There were no significant differences between study groups. Included participants were representative for the HypoDE population regarding demographic data and occurrence of baseline low glucose events.

In both groups together, 910 days of baseline therapy and 922 days of follow-up therapy were evaluated. CGM data were available for at least $92 \%$ of the time under evaluation. Comparison of the 1 week in the baseline phase with the 1 week in the follow-up phase for which logbooks were completed showed a significant difference between the two groups regarding the number of low glucose events. In the rtCGM group, there was a 
decrease from $2.2 \pm 2.4$ events in 1 week to $0.7 \pm 1.3$ events, while it remained unchanged in the control group (from $3.2 \pm 3.3$ to $3.2 \pm 3.2$ events $)(p<0.001)$.

\section{Carbohydrate intake}

Participants in both groups consumed somewhat more than four meals per day (table 2), without changes between baseline and follow-up. Regarding the distribution of meals during the day, a significant increase of $93 \%$ (from $0.15 \pm 0.19$ to $0.29 \pm 0.34$ meal per night vs $0.18 \pm 0.28$ to $0.18 \pm 0.26$ in the control group; $\mathrm{p}=0.008$ ) in the number of meals consumed in the night (00:0006:00) was observed in the rtCGM group, with no significant changes during the other times of the day.

The participant-estimated amount of carbohydrates consumed tended to decrease slightly in both groups (table 2). Insulin dosing for meals was not modified in any group, both maintained the same insulin to carbohydrate ratio during baseline and follow-up.

During the baseline phase, $50 \%$ of participants reported using an injection-meal interval (IMI) $>0 \mathrm{~min}$ for at least one of the main meals. Compared with that, the number of IMI increased in the follow-up phase in the rtCGM group (59\% of participants) and decreased in the control group ( $42 \%$ of participants). The selfreported length of the IMI in those participants who used one during either of the study phases increased by +1.4 min ( -3.1 to 6.0$)(\mathrm{p}=0.533)$ in the morning, $+3.8 \mathrm{~min}$ $(-0.6$ to 8.1$) \quad(\mathrm{p}=0.088)$ for lunch and $+3.8 \mathrm{~min}(0.1-7.4)$ $(\mathrm{p}=0.044)$ in the evening in the rtCGM group without reaching significance in comparison with the control group.

Intake of so-called rescue carbohydrates was observed nearly daily in all participants; however, frequency of doing so was higher in the control group at baseline (table 2). While participants in the control group reduced this frequency by $20 \%$ in the follow-up period, those in the rtCGM group increased the frequency by $20 \%(\mathrm{p}=0.031)$. This increase was most pronounced during the night (from $0.07 \pm 0.12$ to $0.17 \pm 0.20$ per night vs $0.07 \pm 0.14$ to $0.06 \pm 0.13$ in the control group; $\mathrm{p}=0.001$ ). Portion sizes of rescue carbohydrates increased in the control group and decreased in the rtCGM group $(22.3 \pm 9.5 \mathrm{~g}$ to $25.0 \pm 15.8 \mathrm{~g}$ vs $21.5 \pm 10.1 \mathrm{~g}$ to $19.4 \pm 7.8 \mathrm{~g} ; \mathrm{p}=0.028$ ), therefore the total amount of carbohydrates consumed per day for hypoglycemia management did not change (table 2).

The mean individual rescue threshold determined from all rescues of each participant was $70.8 \pm 12.6 \mathrm{mg} /$ $\mathrm{dL} \quad(3.9 \pm 0.7 \mathrm{mmol} / \mathrm{L}) \quad$ and $\quad 70.5 \pm 12.9 \mathrm{mg} / \mathrm{dL}$ $(3.9 \pm 0.7 \mathrm{mmol} / \mathrm{L})$ for control and rtCGM group, respectively. During follow-up, this threshold was raised to $78.8 \pm 14.2 \mathrm{mg} / \mathrm{dL}(4.4 \pm 0.8 \mathrm{mmol} / \mathrm{L})$ in the $\mathrm{rtCGM}$ group, but remained stable in the control group (adjusted difference between groups $+7.6 \mathrm{mg} / \mathrm{dL}$ (2.4-12.8) $(+0.4 \mathrm{mmol} / \mathrm{L}(0.1-0.7)) ; \mathrm{p}=0.005)$ (figure 1). Even though the threshold varied depending on the time of day, a rise could be seen over the whole course of the day (morning $+12.0 \mathrm{mg} / \mathrm{dL} \quad(0.8-23.2) \quad(+0.7 \mathrm{mmol} / \mathrm{L}$
$(0.0-1.3)), \mathrm{p}=0.036$; afternoon $+7.5 \mathrm{mg} / \mathrm{dL}(-1.8$ to 16.8$)$ ( $+0.5 \mathrm{mmol} / \mathrm{L}$ ( -0.1 to 0.9$)$ ), $\mathrm{p}=0.111$; evening $+11.1 \mathrm{mg} /$ $\mathrm{dL}(5.0-17.2)(+0.6 \mathrm{mmol} / \mathrm{L}(0.3-1.0)), \mathrm{p}=0.001$; night $+12.1 \mathrm{mg} / \mathrm{dL} \quad(-56.4$ to 80.6$) \quad(+0.7 \mathrm{mmol} / \mathrm{L} \quad(-3.1$ to $4.5)), \mathrm{p}=0.527$; adjusted differences between groups) .

\section{Insulin therapy}

Insulin doses and distributions are shown in table 2. The rtCGM group applied a slightly higher daily insulin dose than the control group; however, no significant adjustments were made in the rtCGM group compared with the control group in either daily doses of basal or bolus insulin, their proportion or the number of daily injections. Most bolus insulin injections were made in connection with meal intake; no changes in patterns during the day were observed. Regarding the target blood glucose participants used for calculation of their insulin doses, the rtCGM group reported an increase from $119.9 \pm 16.2 \mathrm{mg} / \mathrm{dL}(6.7 \pm 0.9 \mathrm{mmol} / \mathrm{L})$ to $126.0 \pm 20.1 \mathrm{mg} /$ dL $(7.0 \pm 1.1 \mathrm{mmol} / \mathrm{L})$ which was, however, not significant compared with the control group's change $(120.8 \pm 16.5 \mathrm{mg} / \mathrm{dL}(6.7 \pm 0.9 \mathrm{mmol} / \mathrm{L})$ to $121.9 \pm 17.2 \mathrm{mg} /$ $\mathrm{dL}(6.8 \pm 1.0 \mathrm{mmol} / \mathrm{L}))$. Correction factors were calculated from correction bolus doses and the target glucose levels. In the control group, the overall correction factor was lower than in the rtCGM group, but no modification of baseline values was observed in either group, neither when split by time of the day.

\section{Effects of carbohydrate intake and insulin therapy on low glucose events}

Negative binomial regression analysis showed group allocation, baseline low glucose events and rescue threshold are predictors of experiencing low glucose events at follow-up (table 3). Incidence of low glucose events was lower in the rtCGM group (incidence rate ratio (IRR) 0.491 ) and decreased by $2 \%$ (IRR 0.982 ) for every $\mathrm{mg} / \mathrm{dL}$ the rescue threshold was raised. This means a $10 \mathrm{mg} / \mathrm{dL}$ $(0.55 \mathrm{mmol} / \mathrm{L})$ higher rescue threshold would decrease the risk for low glucose events by $20 \%$. This effect was independent of the portion size of rescue carbohydrates, number of measurements and the intraindividual variation of the rescue threshold.

\section{CONCLUSIONS}

The HypoDE study investigated the benefits of rtCGM in people with type 1 diabetes using MDI and having an increased risk for hypoglycemic events. The present analysis provides clinically relevant insights into possible mechanistic associations between the use of rtCGM and the observed reduction of hypoglycemic events, namely adjustments in diabetes therapy.

The following mechanistic associations were identified in participants with impaired hypoglycemia awareness:

1. Based on patient-reported details of carbohydrate consumption and insulin therapy, common therapy factors of participants using rtCGM in this study were not systematically changed. In this sense, no relevant 


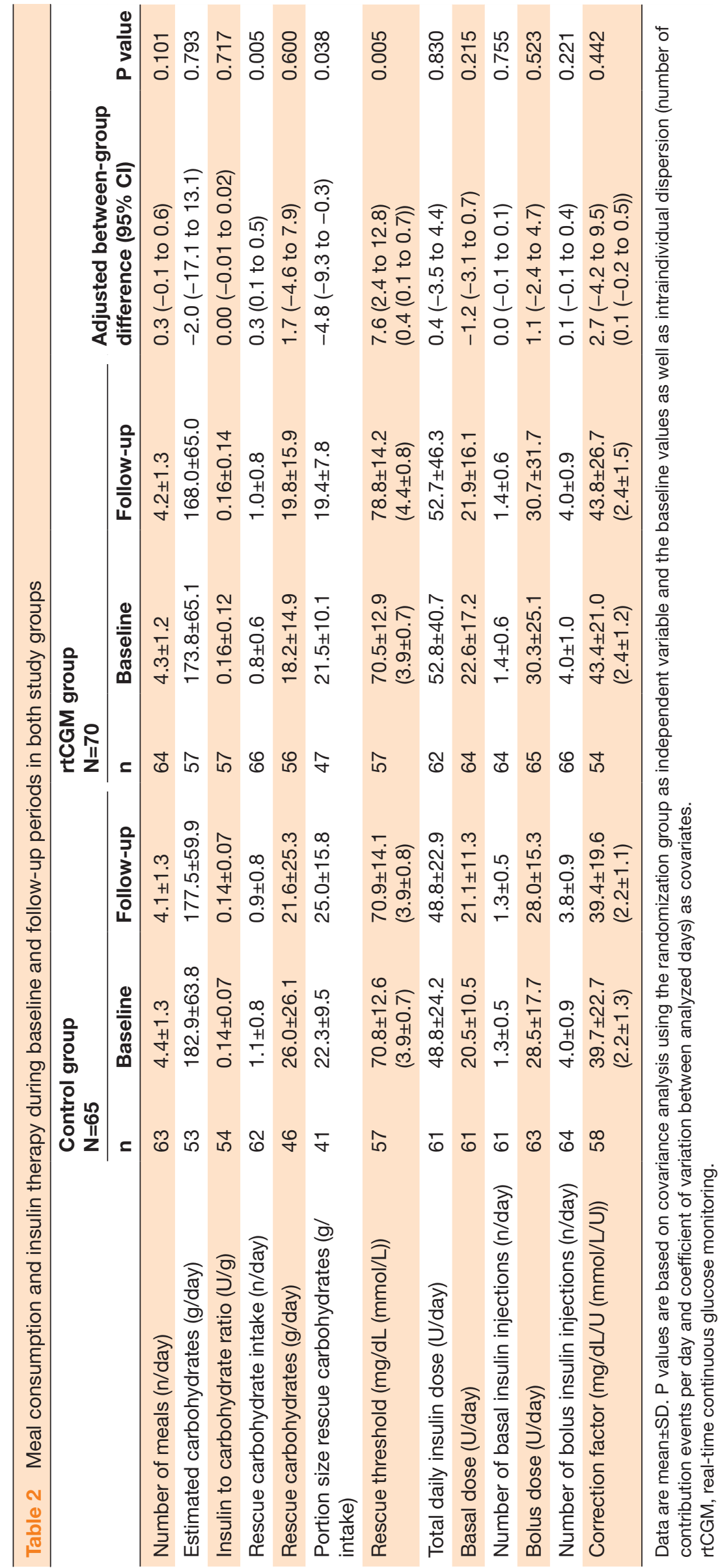




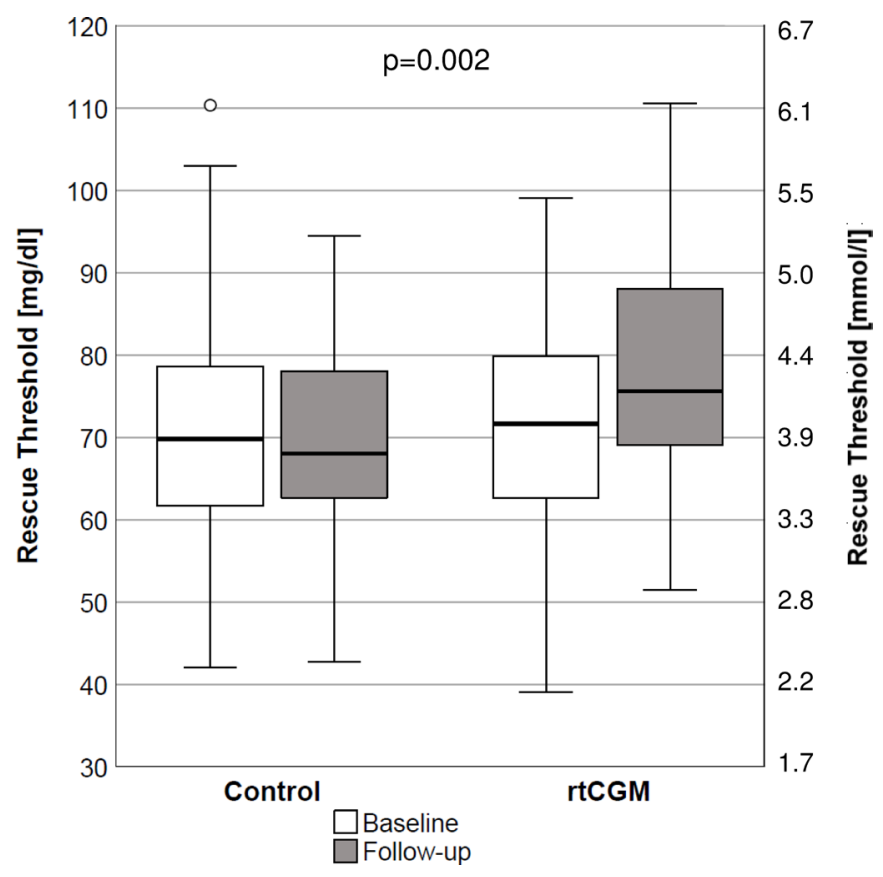

Figure 1 Corresponding glucose values at times of rescue carbohydrate intake during baseline and follow-up phase. rtCGM, real-time continuous glucose monitoring.

modifications regarding insulin dosing were made by participants using rtCGM or treating physicians; participants used the same factors they did when using only SMBG and showed in general the same nutritional behavior.

2. Participants rather made situational behavioral adaptations in their hypoglycemia management; therefore, a behavioral shift from reacting to present hypoglycemia to prophylactically preventing impending hypoglycemia was reached. A better timing of fast-acting carbohydrate intake, that is, an earlier intervention already at higher glucose levels, was identified as being a main predictor for the occurrence of hypoglycemic events.

An rtCGM system, along with adequate training, supports an optimized placing of rescue carbohydrates on the one hand by providing current glucose values continuously and on the other hand through alarms that inform the users even in situations when they are not concerned about their glucose level. With regard to the specific participant population in this study who suffered from impaired hypoglycemia awareness this feature is extremely valuable for the prevention of (severe) hypoglycemic events. The pronounced effectiveness of this rather small action might be a reason why no further systematic adjustments were made; however, the exact reasons were not identified.

Given the lack of systematic therapy adjustments due to the retrospective CGM data analysis, the full potential of rtCGM might still not be exhaustively unfolded. There is, thus, still the potential of enhancing the beneficial effects of CGM if more systematic therapy adjustments were made. Referring to this, advanced training might have supported further options. Results from this study may be used to direct further educational measures for users but also for healthcare professionals, as it provides insight into which adjustments users perceived necessary and which they dared to make. Participants in this study did not receive structured training or education, but were still able to reduce the occurrence of hypoglycemia. Whether structured training in the avoidance of hypoglycemia could lead to additional benefit, and whether such training is cost-efficient, should be assessed in further studies.

Nevertheless, in some aspects or at least in some participants, retrospective analyses were likely used. The intake of smaller portion sizes of rescue carbohydrates, for example, might have been initiated by direct feedback regarding the postprandial glucose curve provided by the CGM system. Similarly, the modifications regarding IMI were most likely made after review of postprandial curves, if deemed necessary. This could explain the decreased glycemic variability reported for rtCGM group participants in HypoDE, ${ }^{6}$ but did not show an effect on the occurrence of low glucose events.

Regression analysis confirmed that the only therapyrelated variables that are independently and significantly associated with the frequency of low glucose events are those related to behavioral changes in spontaneous hypoglycemia management, that is, raising the rescue threshold. While the number of rescue carbohydrate

Table 3 Negative binomial regression model describing predictors for the frequency of low glucose events in the follow-up phase in all participants $(n=135)$

\begin{tabular}{lllr}
\hline Variables & Incidence rate ratio & $\mathbf{9 5 \%} \mathbf{C l}$ & P value \\
\hline Group allocation (rtCGM group) & 0.491 & 0.350 to 0.690 & $<0.001$ \\
\hline Baseline low glucose events & 1.039 & 1.007 to 1.072 & 0.016 \\
\hline Rescue threshold & 0.982 & 0.971 to 0.993 & 0.001 \\
\hline Variation of rescue threshold (intraindividual CV) & 0.741 & 0.247 to 2.227 & 0.594 \\
\hline Number of rescue carbohydrate intakes & 1.063 & 0.957 to 1.181 & 0.255 \\
\hline Variation of number of rescue carbohydrate intakes (intraindividual CV) & 0.892 & 0.701 to 1.134 & 0.350 \\
\hline Portion size rescue carbohydrates & 1.000 & 0.991 to 1.009 & 0.974 \\
\hline
\end{tabular}

$\mathrm{CV}$, coefficient of variation; rtCGM, real-time continuous glucose monitoring. 
intakes was also affected by the number of low glucose events, the rescue threshold seems independent of that. Due to the observed reduction of low glucose events one might expect that rescue carbohydrate intake is also reduced. The observed increased intake, however, supports the importance of rescue carbohydrates and especially distribution and timing as a preventive action. The reduction in rescue carbohydrate portion size might also be a result of the raised threshold. In general, results from the multivariate analysis indicate the importance of human factors in the beneficial effects of rtCGM.

Recommendations on how to use rtCGM data for therapy adjustments mainly describe adjustment of insulin doses based on glucose trends. ${ }^{13-15}$ From the data presented here, it cannot be concluded on whether these recommendations were followed, as trend arrows were not recorded. In addition, the recommendations rather affect individual real-time decisions that depend on current situations. These would unlikely have become visible in this analysis where only mean values of several days and participants were evaluated. Other recommendations focus on the retrospective analysis of ambulatory glucose profiles and subsequent therapy adjustments; however, these focus on when to act rather than how to act in particular. ${ }^{16}$ Therapy adjustments are thus made on an individual case-by-case basis at the discretion of the healthcare professional.

In a survey of 222 well-controlled people with type 1 diabetes, it became obvious that most participants only use glucose information for current treatment decisions instead of analyzing retrospective data to detect patterns and make general adjustments. ${ }^{17}$ The cross-over design of the IN CONTROL study revealed that positive effects of CGM on glycemic control arise rapidly, but are transient and washed out after 12 weeks when CGM use is terminated. ${ }^{18}$ Although therapy adjustments were not systematically assessed in this study, the results do not suggest any systematic modifications but also hint at behavioral changes that are present as long as rtCGM can be used. Participants reported diverging reactions to rtCGM: while some reported becoming more active in adjusting their therapy, others became rather passive relying on alarms. Taken together with the results of the present mechanistic analyses, it is likely that there will be no significant long-term effects once rtCGM use is discontinued, as the identified adjusting screws rely on real-time availability of the system.

It has to be noted that participants of the HypoDE study all had hypoglycemia issues, but apart from that had a good glycemic control. ${ }^{6}$ It can therefore not be excluded that participants with a poor glycemic control would make more extensive self-managed therapy adjustments. In addition, all participants in this study were on MDI therapy which is less flexible than insulin pump therapy. The possibility to adapt insulin delivery in the short term using temporary basal rates, for instance, might have been an alternative to taking rescue carbohydrates likely leading to the same results. For instance, an increased use of temporary basal rates, low glucose suspension and bolus calculator features was reported in continuous subcutaneous insulin infusion (CSII) patients when using rtCGM. ${ }^{7}$

Besides the specific participant group that limits generalization of the presented results to all rtCGM users, this analysis has some further limitations. All information drawn from the logbooks was self-reported. An automated data capture, for example, through smart insulin pens, might have improved data quality. In addition, the level of detail strongly varied between participants and all analyses comprising quantities of carbohydrates rely on participants' estimations if available. Furthermore, variables that required exact time specification like IMI had to be analyzed from descriptions in the questionnaire, because documentation of times of meal intake in the logbooks was not precise enough. A more robust recording would allow a detailed evaluation of the timing aspects. Nevertheless, the findings of this evaluation allow conclusive statements that might be verified in further particular evaluations.

Detailed training about CGM and respective therapy guidance was an indispensable part of the intervention in this study; on the one hand for safety reasons, and on the other hand because it has been shown that without structured training CGM does not achieve the desired effects. ${ }^{19}$ Therefore, it cannot be clearly differentiated whether rtCGM use, training or both caused the behavioral changes. However, in clinical practice, CGM should always be initiated with extensive and appropriate training.

In conclusion, in a population of people with type 1 diabetes with an increased risk for hypoglycemia using MDI, implementation of rtCGM reduced the occurrence of hypoglycemic events without any major therapy adjustments, but by actively preventing the impending hypoglycemia with carbohydrate intake at higher glucose levels.

\section{Author affiliations}

${ }^{1}$ Institut für Diabetes-Technologie, Forschungs- und Entwicklungsgesellschaft mbH an der Universität UIm, Ulm, Germany

${ }^{2}$ Research Institute of the Diabetes Academy Mergentheim, Bad Mergentheim, Germany

${ }^{3}$ Science-Consulting in Diabetes, Neuss, Germany

Acknowledgements We thank Peter Wintergerst (IfDT, Ulm, Germany) for coordination of the study and support of the study sites. We thank all study sites (Gemeinschaftspraxis Drs Klausmann, Dr Gerhard Klausmann (Aschaffenburg, Germany); Diabetologische Schwerpunktpraxis mit Fußambulanz, Dr RalfAchim Bierwirth (Essen, Germany); Medicover Berlin-Mitte, Dr Dorothee Deiss (Berlin, Germany); Diabetologische Schwerpunktpraxis, Dr Matthias Kaltheuner (Leverkusen, Germany); Diabetologische Schwerpunktpraxis, Dr Ralf Kolossa (Bergheim, Germany); Zentrum für Diabetologie Bergedorf, Dr Jens Kröger (Hamburg, Germany); Diabetes-und Stoffwechselzentrum an der Fachklinik Bad Heilbrunn, Dr Andreas Liebl (Bad Heilbrunn, Germany); Diabetologicum Duisburg, Diabetologische Schwerpunktpraxis, Dr Hansjörg Mühlen (Duisburg, Germany); Diabetes Praxis Essen, Dr Helga Zeller-Stefan (Essen, Germany); Diabetes Schwerpunkt Praxis Zentrum für Hormone und Stoffwechsel, Dr Stephan Beck (Marktredwitz, Germany); Schwerpunktpraxis für Diabetes und Ernährungsmedizin, Dr Winfried Keuthage (Münster, Germany); Diabetes Zentrum Mergentheim, Professor Dr Thomas Haak (Bad Mergentheim, Germany) and the study participants for their excellent cooperation and for their effort in the HypoDE study. 
Contributors DW contributed to the coordination of the study, assessed and analyzed the data and wrote the manuscript. GF and LH contributed to design and conduct of the study and to writing and editing of the manuscript. SP and $\mathrm{CH}$ contributed to data analysis and writing and editing of the manuscript. $\mathrm{NH}$ was the principal investigator of the study and contributed to design, conduct and analysis of the study and to writing and editing of the manuscript. DE contributed to writing and editing of the manuscript. DW is the guarantor of this work and, as such, had full access to all the data in the study and takes responsibility for the integrity of the data and the accuracy of the data analysis.

Funding The HypoDE study was funded by Dexcom.

Competing interests DW reports grants paid to employer from Dexcom, during the conduct of the study. GF reports grants from Dexcom, during the conduct of the study; personal fees from Abbott, Novo Nordisk and Ypsomed; grants and personal fees from Roche Diabetes Care and Sanofi; grants from AgaMatrix, Beurer, Dexcom, A Menarini Diagnostics, i-SENS, LifeScan, Metronom, Pharmasens, Profusa, Sensile, outside the submitted work. SP reports grants paid to employer from Dexcom, during the conduct of the study. LH reports grants from Dexcom, during the conduct of the study; personal fees from A Menarini Diagnostics, Becton Dickinson, Lifecare and Roche Diabetes Care, outside the submitted work. LH owns shares of Profil Institut für Stoffwechselforschung, Neuss, Germany and ProSciento, San Diego, USA. NH reports grants and personal fees from Dexcom, during the conduct of the study; grants from AstraZeneca, personal fees from Novo Nordisk and Eli Lilly, grants and personal fees from Abbott Diabetes Care, Berlin Chemie, Ypsomed, and Roche Diabetes Care, outside the submitted work. DE reports grants paid to employer and personal fees from Dexcom, during the conduct of the study and personal fees from Berlin-Chemie, Roche Diabetes Care, Abbott Diabetes Care, and Medtronic outside the submitted work. $\mathrm{CH}$ reports grants paid to employer from Dexcom, during the conduct of the study.

Patient consent for publication Not required.

Ethics approval The study was conducted in compliance with the Declaration of Helsinki; the protocol was approved by the responsible ethics committee at the Landesärztekammer Baden-Wurttemberg, Stuttgart, Germany (reference number: MP-2015-010-ff), and the respective local ethics committees. All participants provided informed consent prior to inclusion.

Provenance and peer review Not commissioned; externally peer reviewed.

Data availability statement Data are available upon reasonable request.

Open access This is an open access article distributed in accordance with the Creative Commons Attribution Non Commercial (CC BY-NC 4.0) license, which permits others to distribute, remix, adapt, build upon this work non-commercially, and license their derivative works on different terms, provided the original work is properly cited, appropriate credit is given, any changes made indicated, and the use is non-commercial. See: http://creativecommons.org/licenses/by-nc/4.0/.

ORCID iDs

Delia Waldenmaier http://orcid.org/0000-0003-3280-2369

Guido Freckmann http://orcid.org/0000-0002-0406-9529

Stefan Pleus http://orcid.org/0000-0003-4629-7754

\section{REFERENCES}

1 American Diabetes Association. 7. Diabetes Technology: Standards of Medical Care in Diabetes-2020. Diabetes Care 2020;43:S77-88.

2 Rodbard D. Continuous glucose monitoring: a review of recent studies demonstrating improved glycemic outcomes. Diabetes Technol Ther 2017;19:S-25-37.

3 Ly TT, Nicholas JA, Retterath A, et al. Effect of sensor-augmented insulin pump therapy and automated insulin suspension vs standard insulin pump therapy on hypoglycemia in patients with type 1 diabetes: a randomized clinical trial. JAMA 2013;310:1240-7.

4 van Beers CAJ, DeVries JH, Kleijer SJ, et al. Continuous glucose monitoring for patients with type 1 diabetes and impaired awareness of hypoglycaemia (in control): a randomised, open-label, crossover trial. Lancet Diabetes Endocrinol 2016;4:893-902.

5 Little SA, Speight J, Leelarathna L, et al. Sustained reduction in severe hypoglycemia in adults with type 1 diabetes complicated by impaired awareness of hypoglycemia: two-year follow-up in the HypoCOMPaSS randomized clinical trial. Diabetes Care 2018:41:dc172682-7.

6 Heinemann L, Freckmann G, Ehrmann D, et al. Real-time continuous glucose monitoring in adults with type 1 diabetes and impaired hypoglycaemia awareness or severe hypoglycaemia treated with multiple daily insulin injections (HypoDE): a multicentre, randomised controlled trial. Lancet 2018;391:1367-77.

7 Battelino T, Conget I, Olsen B, et al. The use and efficacy of continuous glucose monitoring in type 1 diabetes treated with insulin pump therapy: a randomised controlled trial. Diabetologia 2012;55:3155-62.

8 Lind M, Polonsky W, Hirsch IB, et al. Continuous glucose monitoring vs conventional therapy for glycemic control in adults with type 1 diabetes treated with multiple daily insulin injections: the gold randomized clinical trial. JAMA 2017;317:379-87.

9 Beck RW, Riddlesworth T, Ruedy K, et al. Effect of continuous glucose monitoring on glycemic control in adults with type 1 diabetes using insulin injections: the diamond randomized clinical trial. JAMA 2017;317:371--8.

10 Juvenile Diabetes Research Foundation Continuous Glucose Monitoring Study Group. Effectiveness of continuous glucose monitoring in a clinical care environment: evidence from the juvenile diabetes research Foundation continuous glucose monitoring (JDRFCGM) trial. Diabetes Care 2010;33:17-22.

11 Clarke WL, Cox DJ, Gonder-Frederick LA, et al. Reduced awareness of hypoglycemia in adults with IDDM. A prospective study of hypoglycemic frequency and associated symptoms. Diabetes Care 1995;18:517-22.

12 Heinemann L, Deiss D, Hermanns N, et al. HypoDE: Research Design and Methods of a Randomized Controlled Study Evaluating the Impact of Real-Time CGM Usage on the Frequency of CGM Glucose Values $<55 \mathrm{mg} / \mathrm{dl}$ in Patients With Type 1 Diabetes and Problematic Hypoglycemia Treated With Multiple Daily Injections. J Diabetes Sci Technol 2015;9:651-62.

13 Pettus J, Edelman SV. Recommendations for using real-time continuous glucose monitoring (rtCGM) data for insulin adjustments in type 1 diabetes. J Diabetes Sci Technol 2017;11:138-47.

14 Ziegler R, von Sengbusch S, Kröger J, et al. Therapy adjustments based on trend Arrows using continuous glucose monitoring systems. J Diabetes Sci Technol 2019;13:763-73.

15 Aleppo G, Laffel LM, Ahmann AJ, et al. A practical approach to using trend Arrows on the Dexcom G5 CGM system for the management of adults with diabetes. J Endocr Soc 2017;1:1445-60.

16 Kröger J, Reichel A, Siegmund T, et al. Clinical recommendations for the use of the ambulatory glucose profile in diabetes care. J Diabetes Sci Technol 2020;14:1932296819883032.

17 Pettus J, Price DA, Edelman SV. How patients with type 1 diabetes translate continuous glucose monitoring data into diabetes management decisions. Endocr Pract 2015;21:613-20.

18 Vloemans AF, van Beers CAJ, de Wit M, et al. Keeping safe. continuous glucose monitoring (CGM) in persons with type 1 diabetes and impaired awareness of hypoglycaemia: a qualitative study. Diabet Med 2017;34:1470-6.

19 Foster NC, Beck RW, Miller KM, et al. State of type 1 diabetes management and outcomes from the T1D exchange in 2016-2018. Diabetes Technol Ther 2019;21:66-72. 